\title{
Anestesia para resonancia nuclear magnética. Revisión de 3.018 casos
}

\author{
Sylvia Verónica Benedetto², Verónica Benedetto , Benjamín Silberman", Joaquín Monsalve, \\ Macarena Ahumada², Lorena Iturra ${ }^{1}$
}

Introducción: Los procedimientos realizados bajo anestesia general fuera de pabellón representan un desafío para el anestesiólogo, a su vez, la necesidad de contar con imágenes precisas para el diagnóstico de diversas patologías han llevado a incrementar el número de resonancias magnéticas solicitadas a lo largo de los años por distintas especialidades de la medicina. Realizamos la revisión de los protocolos de anestesia del Centro Radiológico Fleming entre los años 2010 y 2016 con el fin de caracterizar la población de pacientes atendidos y sometidos a algún procedimiento anestésico y evaluar la técnica usada.

Objetivo: Realizar estudio descriptivo de la población sometida a anestesia para resonancia nuclear magnética en Centro Radiológico Fleming durante los últimos 7 años. Describir la técnica empleada y evaluar la seguridad de esta así como el aporte en la correcta realización del examen radiológico.

Material y Método: Se revisan protocolos de anestesia de todos los pacientes atendidos extrayendo datos demográficos y técnica anestésica empleada. Una vez completada la base de datos se realizo análisis estadístico.

Resultados: 3.018 pacientes fueron atendidos y sometidos a anestesia general durante los 7 años. Para ellos se utilizo anestesia general con inducción inhalatoria con sevofluorano o mixta con sevofluorano + propofol, mantención con sevofluorano, ventilación con máscara laringea y relajo muscular solo en caso de necesidad del examen o del paciente con mivacurio. Todos se realizaron con monitorización básica. Del total de la población estudiada, 75\% $(n=2.240)$ correspondieron a pacientes pediatricos y $25 \%$ ( $n$ $=778$ ) adultos, entre los cuales se incluyen recién nacidos y adultos mayores. El $48 \%$ de los pacientes fueron clasificados como ASA I, otro 48\% ASA II y un 4\% ASA III. La técnica anestesica inhalatoria fue la más utilizada con un $71 \%$ de los casos, recibiendo el resto de los pacientes una técnica mixta inhalatoria endovenosa en la inducción, con posterior mantención con gas. Del total de pacientes, el $92 \%$ mantuvo ventilación espontánea durante el procedimiento, siendo necesaria la ventilación manual asistida exclusivamente para exámenes de abdomen y tórax que requirieron relajo muscular. De los estudios solicitados, lidera la RNM de cerebro con un $60 \%$ seguido de los procedimientos de columna con un $19 \%$. No se registraron complicaciones relacionadas a la anestesia en los casos revisados y todos los pacientes fueron dado de alta de la Unidad, ya sea a su domicilio o a su hospital de origen, una vez completada la recuperación post anestesica sin incidentes.

Conclusiones: Con los datos obtenidos en la revisión, se concluye que la técnica anestesica empleada para RNM en el Centro es segura, tanto para pacientes sanos como aquellos que padecen enfermedades agregadas, compensadas o no, en todas las etapas de la vida, desde recién nacidos a adultos mayores. Todos los procedimientos se realizaron de forma ambulatoria, sin presentar complicaciones en ninguno de los casos revisados. Concluimos además que la inducción y mantención con gases durante la realización del examen RNM es eficiente, siendo un aporte para la correcta realización del examen imagenológico en relación a calidad y tiempo. 